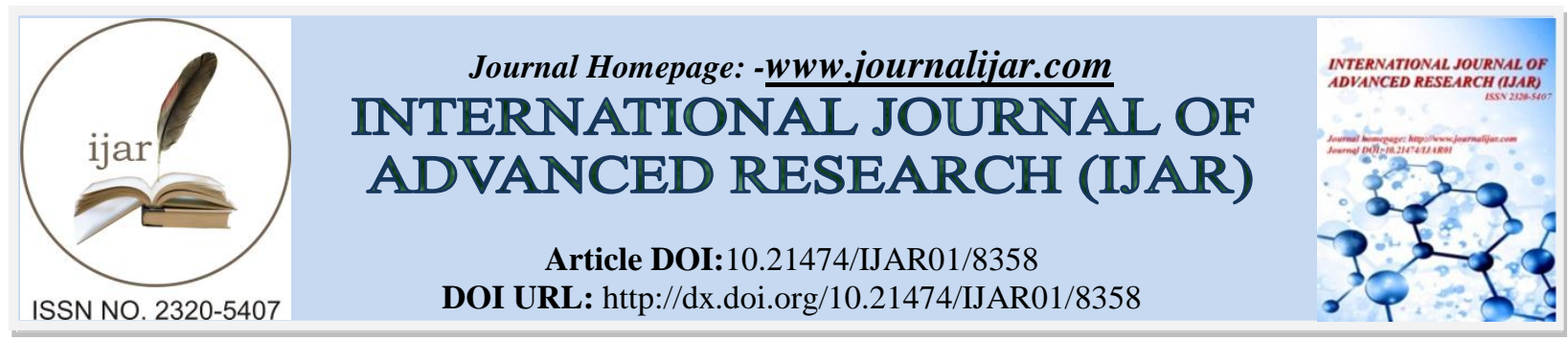

RESEARCH ARTICLE

\title{
COMPARATIVE STUDY OF IMMUNOLOGICAL METHODS FOR THE DIAGNOSIS OF CHLAMYDIA TRACHOMATIS IN WOMEN WITH CERVICITIS AND INFERTILITY.
}

\author{
Abrar A. H. Sahi, Khairallah A.S. Mohammed and Zainab Y. Al Salman. \\ 1. Southern Technical University, Health \& Medical Technology College, Basrah/Iraq. \\ 2. Basra Hospital for Women and Children, Basrah /Iraq.
}

\section{Manuscript Info}

Manuscript History

Received: 08 November 2018

Final Accepted: 10 December 2018

Published: January 2019

\section{Key words:-}

Chlamydia trachomatis, female infertility, cervicitis, ELISA, Rapid Test, endocervical swabs

\begin{abstract}
We have evaluated the diagnostic accuracy of three ELISA tests (IgM, $\operatorname{IgG}, \operatorname{IgA}$ ) and rapid test in detecting $C$. trachomatis by comparing with direct immunofluorescence (DIF), which is used as a gold standard. Blood samples and endocervical swabs of 100 suspectedfemales and 10 healthy women were collected. All sera were tested for chlamydial antibodies of the IgG, IgM and IgA classes by ELISA. Swabs were tested by Rapid test and DIF for detection of C. trachomatis antigen. Among 100 patients that were included in the study, 46 (46\%) women with infertility and $4(4 \%)$ with cervicitis were positive for chlamydia according to the standard method (DIF). None of the healthy women was positive. When compared to DIF results; the ELISA (IgM, IgG, $\operatorname{IgA}$ ) and rapid test results showed noteworthy differences in the major performance characteristics. The sensitivity of $\operatorname{IgM}, \operatorname{IgA}, \operatorname{IgG}$ and Rapid test was (66, 62, 48, and 24\%), specificity $(96,96,92$, and 94\%), positive predictive values $(94.3,93.3,58.7$, and $80 \%$ ), negative predictive values $(73.8,71.6,63.9$, and 55.3\%) and Area Under a Curve $(0.81,0.81,0.7,0.59 .3 \%)$ respectively. The results concluded that DIF, $\operatorname{IgM}$, and $\operatorname{IgA}$ are valuable techniques to diagnose chlamydial infections. On the other hand, under the conditions of our study, the results suggested that IgG and rapid test are not reliable for diagnosis of chlamydial infections.
\end{abstract}

Copy Right, IJAR, 2017,. All rights reserved.

\section{Introduction:-}

Chlamydia trachomatis infection is the most common prevalent sexually transmitted infection worldwide (1). In 2012, WHO reported that there were about 130.9 million people that are infected yearly with $C$. trachomatis (1).The rate of infection is different worldwide (1). In Iraq, the rate of chlamydial infection reached $9.6 \%$ as reported in a study carried out in 1990 (2). AL-Husseineiet. al., 2009, used Enzyme linked fluorescent assay technique and found that $12.8 \%$ of suspected women were infected with C. trachomatis (3). In 2009 Abdul-Karim et al, used ELIZA technique and stated that $20 \%$ of total 277 women tested were positive for IgG antibody against C. trachomatis (4).Other studies carried in Baghdad city reported that $85.96 \%$ are positive for $\operatorname{IgM}$, IgG and 59.64\% for $\operatorname{IgA}$ Chlamydial Abs in serum of suspected pregnant-women (5). Ahmed, 2012, used PCR technique and found that 26.5 $\%$ out of 147 endocervical women swabs were positive for Chlamydia infection (6).In Basra, the first study of $C$. trachomatis was carried by Tahir at 2016 and found that out of 200 infertile women $48 \%$ were PCR positive and

Corresponding Author:-Abrar A. H. Sahi.

Address:-Southern Technical University, Health \& Medical Technology College, Basrah/Iraq. 
$11 \%$ and $5.5 \%$ were sero-positive for $\operatorname{IgM}$ and $\operatorname{IgG}$ antibodies (7). The variation of the positive results among many studies of diagnosis of $C$. trachomatis, in Iraq, might be due to the number and subject's status, specimen collection techniques, transport time or methodology.

Urogenital infections with $C$. trachomatis, in women, can lead to pelvic inflammatory disease associated with late ectopic pregnancy and tubal infertility $(8,9)$. More than $40 \%$ offemales with untreated $C$. trachomatis infection may develop PID and about $20 \%$ of them become infertile, $18 \%$ results in chronic pelvic pain $(8,9)$. Additionally, women with chlamydial infection have 3-4 fold amplified risk of acquiring HIV and developing invasive cervical cancer $(8,9)$. Also, asymptomatically infected women may develop reproductive squeal. Therefore, screening and diagnosis of genital chlamydial infection is a high public health concern(10)Furthermore, thehigh level of chlamydial infection prevalence has produced considerable attention in development of sensitive, specific, cost effective, and rapid techniques for diagnosis of this disease (11). Bacterial isolation in tissue culture media and a nucleic acid amplification test (NAAT) are generally regarded as a gold standard for the diagnosis of Chlamydia trachomatis infection. However, culture method requires careful specimen collection and stringent transport condition and requires at least 48 to $72 \mathrm{~h}$ to perform $(12,13)$. On other hand, DNA amplification technique might not be cost effective for screening program in developing countries (14).

Many studies suggested that Chlamydial serology could be useful to detect current, chronic or persistent chlamydial infection, and for screening women with asymptomatic chlamydial infection (15-19). The aim of this study was to evaluate the diagnostic accuracy of different immunological methods in the diagnosis of Chlamydia trachomatis in cervicitis and infertile women.

\section{Method:-}

\section{Patient population:-}

Between October 2017 and August 2018, a total of 100 women, aged $15-42$, with cervicitis and infertility and 10 apparently healthy women, who attended cervical cancer and infertility at Basra Hospital for Women and Children (Basrah - Iraq), were recruited in the present study. After examination by physicians, informed consent was obtained from all patients, and a questionnaire regarding, age, level of education, job, marital status, history of genital infections, history of aborting, contraceptive methods, history of genital surgery and symptoms was completed.

\section{Samples collection:-}

Five ml of blood, from each participant, used for serological tests, and two endocervical swabs (cytologybrush swab \& cotton polyester swab) from each contributor were collected, one of which was used for the direct immunofluorescence (DIF) and the other used for rapid test.

\section{Dif Test:-}

The swab specimen, used for DIF, was rolled using slight pressure, within the $6 \mathrm{~mm}$ well area on the microscope slide. The specimen was allowed to air dry thoroughly at room temperature $\left(15-30^{\circ} \mathrm{C}\right)$ and then fixed in fresh acetone for 10 minutes and allowed to air dry. The slides were subjected to the technique using a direct immunofluorescence test for the detection of Chlamydia trachomatis (IMAGEN Chlamydia, Oxoid, UK), according to the manufacturer's instructions and examined with a fluorescence microscope. The smears were investigated for the presence of extracellular elementary bodies (EBs) which appear as very small bright apple-green fluorescent smooth edged disc shapes approximately $300 \mathrm{~nm}$ in diameter observed against background of a red counterstained cells and cellular debris (Fig. 1). The samples were considered positive if they presented at least ten EBs per slide, cut-off recommended by the manufacturer. The absence of Chlamydia bodies was considered negative.

\section{Rapid Test:-}

For rapid test the swabspecimen was immersed into the extraction tube and processed according to the manufacturer's recommendations (Chlamydia trachomatics antigen rapid test kit, PreCheck BIO), the results were interpreted against the positive and negative controls provided by the manufacture.

\section{EIIZA Test:-}

Sera were prepared from blood specimens and analysed by enzyme-linked immunosorbent assay for detection of immunoglobulin $\mathrm{G}$ and $\mathrm{M}$ and $\mathrm{A}$ antibodies to Chlamydia trachomatis. The technique used for the ELISA was according to the manufacturer's recommendations (Chlamydia trachomatis IgG ELIZA kit, AccuDiag; Chlamydia 
trachomatis IgM ELIZA kit, AccuDiag, USA; Chlamydia trachomatis IgA, NOVA TEC, Germany). The reading of the results were interpreted by using a cutoff absorbance based on the absorbance of known negative and positive controls supplied by the manufactures.

\section{Statistical analysis:-}

The performances of ELIZA (IgG, IgM and IgA) and Rapid test were compared with that of DIF. Statistical analysis was carried out by using the statistical package for social sciences (SPSS) version 22 and graphic pad prism version 6. The sensitivity, specificity, positive predictive value, negative predictive value, Area Undera Curve of each method tested were calculated and compared with the that ofthe gold standard (DIF). Chi-square (x2) was applied in the comparison of employed tests with the gold standard and the statistical significance was set at less than $5 \%$ level.

\section{Results:-}

A comparison of the five immunological tests showed noteworthy differences in the major performance characteristics (Table 1). Out of 100-suspected cases that were enrolled in this study, 15\% (15) were positive for the rapid test, 35\% (35) were positive for anti-chlamydial IgM Abs, 33\% (33) were positive for anti-chlamydial IgA Abs, 28\% (28) were positive for anti-chlamydial IgG Abs and 50\% (50) were positive for DIF (Table 1).

The results of the present study showed that the positivity of rapid test in comparing with positive DIF was (24\%), with significant difference $(\mathrm{P}<0.05)$. The sensitivity and specificity of this test were $(24 \%$ and $94 \%)$ respectively. The PPV and NPV values were (80.0\% and 55.29\%). Additionally, the Area Under a Curve (AUC) was (0.59) as shown in table 1.

The positivity of anti-chlamydial IgM Abs in comparing with positive DIF was (66.0\%) with significant difference $(\mathrm{P}<0.05)$. The sensitivity and specificity of anti-chlamydial IgM Abs were $(66.0 \%$ and $96.0 \%)$ with PPV and NPV values of $(94.28 \%$ and $73.84 \%)$ correspondingly. The AUC value was 0.81 as shown in table 1.

The results showed that the positivity of anti-chlamydial IgA Ab compared with positive DIF was (62.0\%) with significant difference $(\mathrm{P}<0.05)$. The sensitivity and specificity of anti-chlamydial IgA Ab were $(62 \%$ and $96 \%)$ with PPV and NPV values of (93.93\% and 71.64\%) respectively. The AUC value was (0.81) as shown in table 1.

The positivity of anti-chlamydial IgG Abs in comparing with DIF was $48 \%$ with significant difference $(\mathrm{P}<0.05)$. The sensitivity and specificity of anti-chlamydial IgG Abs were (48.0\% and $92.0 \%)$ with PPV and NPV values of $(68 \%$ and $88 \%)$ respectively. The AUC value of this test was $(0.70)$ as shown in table 1.

The highest percentage of infection (75\%) was observed in women aged 20 - 39. The illiterate and primary education and low socio-economic status showed high rate of infection. The comparison of obtained positive results with the histopathological finding showed that $35 \%$ and $10 \%$ of acute and chronic cervicitis respectively, $7.5 \%$ of CIN1 and $47.5 \%$ normal.The cervical appearance by inspection was about $15 \%$ bleeding on touch and $35 \%$ eroded with bleeding on touch and 50\% normal. Patients with abortion showed $42.5 \%$ of the positive results and $57.5 \%$ without. Infertile women showed $87.5 \%$ of the positive results.
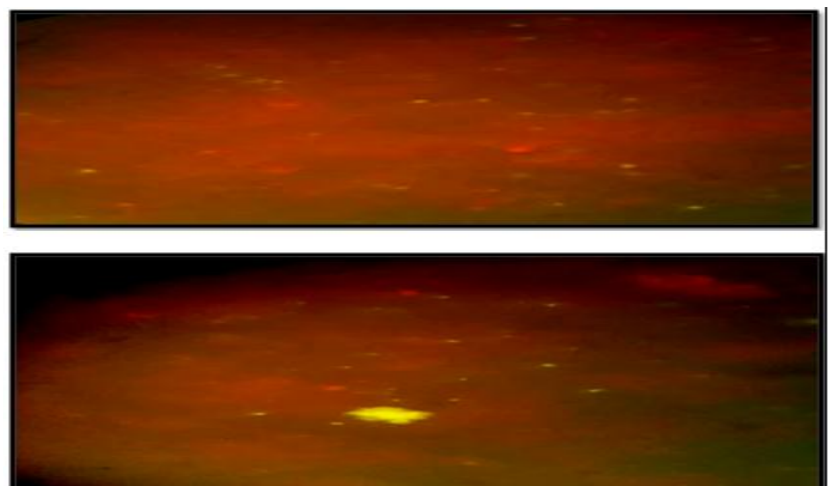

Figure 1:-Immunofluorescence microscopy (X1000 magnification) of Chlamydia trachomatis infected cells for endocervical swab slides showing extracellular elementary bodies (cut-off $\geq 10 \mathrm{EBs}$ ). EBs appear as a very small bright appel-green fluorescent smooth edged disc shapes approximately 300nm in diameter and can be observed against a background of red counterstained cells and cellular debris. 
Table 1:-Comparison of immunological parameters within study subjects depending on DIF positivity of C.trachomatis.

\begin{tabular}{|c|c|c|c|c|}
\hline Test type & $\begin{array}{l}\text { DIF } \\
\text { Positive }\end{array}$ & $\begin{array}{l}\text { DIF } \\
\text { Negative }\end{array}$ & Total & STATISTICS \\
\hline $\begin{array}{l}\text { Rapid test } \\
\text { Positive } \\
\text { Negative } \\
\text { Total }\end{array}$ & $\begin{array}{l}12 \\
38 \\
50\end{array}$ & $\begin{array}{l}3 \\
47 \\
50\end{array}$ & $\begin{array}{l}15 \\
85 \\
100\end{array}$ & $\begin{array}{l}\mathrm{X}^{2}=6.35, \quad * \mathrm{P}=0.01 \\
\mathrm{SP}=94.0 \% . \quad \mathrm{Sn}=24.0 \% \\
\mathrm{PPV}=80.0 \%, \quad \mathrm{NPV}=55.29 \% \\
\mathrm{AUC}=0.59\end{array}$ \\
\hline $\begin{array}{l}\text { IgM } \\
\text { Positive } \\
\text { Negative } \\
\text { Total } \\
\end{array}$ & $\begin{array}{l}33 \\
17 \\
50\end{array}$ & $\begin{array}{l}2 \\
48 \\
50 \\
\end{array}$ & $\begin{array}{l}35 \\
65 \\
100\end{array}$ & $\begin{array}{l}\mathrm{X}^{2}=42, \quad * \mathrm{P}=0.001 \\
\mathrm{SP}=96.0 \%, \quad \mathrm{Sn}=66.0 \% \\
\mathrm{PPV}=94.28 \%, \quad \mathrm{NPV}=73.84 \% \\
\mathrm{AUC}=0.81\end{array}$ \\
\hline $\begin{array}{l}\text { IgA } \\
\text { Positive } \\
\text { Negative } \\
\text { Total } \\
\end{array}$ & $\begin{array}{l}31 \\
19 \\
50 \\
\end{array}$ & $\begin{array}{l}2 \\
48 \\
50 \\
\end{array}$ & $\begin{array}{l}33 \\
67 \\
100 \\
\end{array}$ & $\begin{array}{l}\mathrm{X}^{2}=38, \quad * \mathrm{P}=0.001 \\
\mathrm{SP}=96.0 \%, \quad \mathrm{Sn}=62.0 \% \\
\mathrm{PPV}=93.93 \%, \quad \mathrm{NPV}=71.64 \% \\
\mathrm{AUC}=0.81\end{array}$ \\
\hline $\begin{array}{l}\text { IgG } \\
\text { Positive } \\
\text { Negative } \\
\text { Total }\end{array}$ & $\begin{array}{l}24 \\
26 \\
50\end{array}$ & $\begin{array}{l}4 \\
46 \\
50 \\
\end{array}$ & $\begin{array}{l}28 \\
72 \\
100 \\
\end{array}$ & $\begin{array}{l}\mathrm{X}^{2}=20, \quad * \mathrm{P}=0.001 \\
\mathrm{SP}=92.0 \%, \quad \mathrm{Sn}=48.0 \% \\
\mathrm{PPV}=85.71 \%, \quad \mathrm{NPV}=63.88 \% \\
\mathrm{AUC}=0.70\end{array}$ \\
\hline
\end{tabular}

(*) Significant difference. (NS) non-Significant difference. (X2) Chi-square.. (P value) Probability. (Sn) Sensitivity. (Sp) specificity. (PPV) Predictive positive value and (PNV) predictive negative value, (AUC) Area Under a Curve

\section{Discussion:-}

The manifestation and consequences of $C$. trachomatis infections are more damaging to reproductive health in women than in men, so they are considered an important issue in women's healthcare $(8,9)$. Therefore, using specific and sensitive technique is essential to establish accurate diagnosis of chlamydial infections. Yet, there is no clinical or microbiological reference standard for diagnosis of $C$. trachomatis infection (20). Culture is no longer considered as a reference microbiological method because of the low sensitivity (75\% to 85\%) compared to PCR (21). In addition, the endocervical culture is an unreliable method to rule out the presence of endometrial or tubal pathogens, as the pathogen is not always present at the culture site (22). Therefore, the Immunological and PCR techniques are useful and reliable methods for the detection of $C$. trachomatis in endocervical swab and serum specimens (22). However, DNA Amplification technique might not be cost effective for screening programs in developing countries (14). Moreover, serological tests may be helpful in the diagnosis of chronic and invasive chlamydial infections such PID in which bacteria are undetectable in urogenital swabs or urine (23). In addition, persistent chlamydial infections and subsequent complications are usually associated with a positive antibody response; negative serology may exclude the chlamydial infection (23).

In this study, we used different immunological methods to diagnose chlamydial infections. The validity and the diagnostic accuracy of each method tested was quantified by measuring the sensitivity, specificity, positive and negative predictive values (PPV and NPV), the Area Under a Curve (AUC), of each test result and compared with that of DIF as a gold standard method. P value $<0.05$ was considered as a significant value (24). The selection of DIF as a gold standard was based on that, the validity of this technique was establishedby many studies $(25,26,27)$.The comparison of DIF and culture showed that the range of DIF sensitivity between 80 to $90 \%$ and specificity was 98 to $99 \%(28)$.

Sensitivity defined as the probability of getting a positive test result in subjects with disease and specificity defined as the probability of a test to exclude a positive test result in subjects without the disease $(24,29)$. In the present study, the comparison of serological results with DIF showed highest sensitivity of $\operatorname{IgM}$ and IgA tests $(66.0 \%$ and $62.0 \%$ respectively, table 1 ) comparing with low sensitivity of $\mathrm{IgG}$ and rapid test (48.0\% and $24.0 \%$ respectively, table 1).These findings indicate that $\operatorname{IgM}$ and $\operatorname{IgA}$ have highest sensitivity among the serological tests used in this study. That may be due to the current infection or reinfection leading to high level of $\operatorname{IgM}$ and $\operatorname{IgA}$ in patient's 
serum. On other hand, the rapid test showed the lowest sensitivity, which may be due to the low load of bacteria in the specimens, sample collection method or sample processing. These results agree with other studies, which demonstrated a low sensitivity of rapid tests $(30,31)$.

The specificity of IgM and IgA tests was $96.0 \%$ for both, with PPV 94.3\% and 93.9\%, respectively (table 1). The results revealed that the specificity of IgM and IgA tests approaches $100 \%$ and the PPV above $90 \%$ which approving that no false positive results will be expected according to the CDC guidelines for chlamydial diagnosis and other studies $(31,32)$. Therefore, the positive results of these tests do not need to be confirmed by other test. The NPV values of $\operatorname{IgM}$ and $\operatorname{IgA}$ were $73.8 \%$ and $71.6 \%$, which indicate that the probability of having false negative results about $28 \%$. This may be due to low sensitivity of the both test.

PPV defines the probability of having a disease of interest in a subject with a positive result and NPV probability of not having a disease in a subject with a negative result, unlike sensitivity and specificity, predictive values depend on the diseases prevalence in examined population $(29,30)$. We found that the specificity of IgG and rapid test was $92 \%$ and $94 \%$ with PPV $85.78 \%$ and $80 \%$ and NPV values $63.88 \%$ and $55.29 \%$ respectively. Based on the low sensitivity $(48,24 \%$ respectively) and PPV values, witha high probability of getting false positive results, the tests may needto be supplemented by another confirmatory.

Other measures of diagnostic accuracy used in this study is the ROC curve and the Area Under a Curve AUC, which helps to estimate the discriminative power of a given test. The diagnostic accuracy is determined by the value of AUC; the highest value of AUC $(0.9-1.0)$ is the best and the lowest value $(<0.5)$ means the test is useless. The present comparative study concluded that the AUC value in addition to other measurements proved that the IgM and IgA tests are more reliable serological tests, which could be used to diagnose acute and persistent chlamydial infections, preferably combined. On other hand, under the conditions of our study, the results indicated that IgG and rapid test are not trustworthy for diagnosis of chlamydial infections.

\section{References:-}

1. WHO guidelines for the treatment of Chlamydia trachomatis; 9789241549714 (2016). World Health Organization: WHO Document Production Services, Geneva, Switzerland.

2. Mohammed, N.S.; AL-Omari, W.R. and AL-Ani. T. A. (1990). Interrelationship of Chlamydia subgroup and other pathogens in the female genital tract. Journal of the Faculty of Medicine. Baghdad,32(3):339.

3. AL-HusseineiRaad, K.,Khadaem, Khamael M.,AL-Janabi A. Lamya, and FatheiMun'im M. (2009). ELFA and IFAT techniques to detect Chlamydia infection in Baghdad women and It's effect on theimmunoglobulin level. Journal of the Faculty of Medicine,Baghdad, 51(2), 192-197.

4. Abdul Karim, E.T., Abdul Muhymen, N. \& Al Saadie, M. (2009). Chlamydia trachomatis and rubella antibodies in women with full-term deliveries and women with abortion in Baghdad. Eastern Mediterranean Health Journal, 15(6), 1407-1411

5. Al-Hamdani M. Suhad, Shemran A. Haider, Haider S Kadhim and Hassan Yasser (2010). Prevalence of antiChlamydial Immunoglobulin in pregnant women. Journal of Collage of Educationl, Iraq (1),95-70.

6. Ahmed T. Shatha(2012). Detection of Chlamydia trachomatis using Polymerase Chain Reaction PCR. Baghdad University /Science Collage for women /Biology Department.Al- Mustansiriyah Journal of Science,23(6), 3542.

7. Tahir, M. A. (2016). Molecular and serological detection of Chlamydia trachomatis among infertile women in Basra (Unpublished master's thesis). University of Basrah, Medicine College, Basrah.

8. Price, M. J., Ades, A. E., Welton, N. J., Simms, I., Macleod, J., \& Horner, P. J. (2016). Proportion of Pelvic Inflammatory Disease Cases Caused by Chlamydia trachomatis: Consistent Picture From Different Methods. Journal of Infectious Diseases, 214(4), 617-624.

9. Lanjouw, E., Ossewaarde, J. M., Stary, A., Boag, F., \& Van der Meijden, W. I. (2010). 2010 European guideline for the management of Chlamydia trachomatis infections. International Journal of STD \& AIDS, 21(11), 729-737.

10. Morre, S. A., 1 1. Rozendaal,1 i. G. M. Van valkengoed,2 a. J. P. Boeke,2 p. C. Van voorst vader,3 j. Schirm, s. De blok,5 j. A. R. Van den hoek,6 g. J. J. Van doornum,6 c. J. L. M. Meijer,1 and a. J. C. Van den brule1 (2000). Urogenital Chlamydia trachomatis Serovars in Men and Women with a Symptomatic or Asymptomatic Infection: an Association with Clinical Manifestations?. JOURNAL OF CLINICAL MICROBIOLOGY, 38(6), 2292-2296 
11. Barnes, R. C. (1989). Laboratory diagnosis of human chlamydial infections. Clinical Microbiology Reviews, 2(2), 119-136.

12. Piémont y., jaulhac b. (1995): use of molecular methods for bacteriology diagnosis. Annales de dermatologieet de vénéréologie, 122, 206-12.

13. Osewaarde JM, Rieffe M, Rozenberg-Arska M, et al. (1992): Development and clinical evaluation of polymerase chain reaction tests for detection of Chlamydia trachomatis. Journal of ClinicalMicrobiology,30(8), 2122-2128.

14. Crotchfelt, K.A. Welesh,L.E. Debonville, D. Rosenstraus, M. Quinn,T.C.(1997). Detection of Neisseria gonorrhoeaeand Chlamydia trachomatis in genitourinary specimens from men and women by a coamplification PCR assay. Journal of Clinical Microbiology,35(6),1536-40.

15. Baud, D., Regan, L., \&Greub, G. (2010). Comparison of five commercial serological tests for the detection of anti-Chlamydia trachomatis antibodies. European Journal of Clinical Microbiology \& Infectious Diseases, 29(6), 669-675.

16. Shulman, L. (2012). Chlamydia trachomatis Antigens Recognized in Women With Tubal Factor Infertility, Normal Fertility, and Acute Infection. Yearbook of Obstetrics, Gynecology and Women's Health, 2012, 305306.

17. Halvorsen, D. S., Borvik, T., Njolstad, I., Gutteberg, T. J., Vorland, L. H., \& Hansen, J. (2002). Chlamydia pneumoniae IgA- and IgG antibodies in young survivors of myocardial infarction. A comparison of antibody detection by a microimmunofluorescence test and an enzyme immunoassay. Journal of Internal Medicine, 251(2), 142-147.

18. Jones, C. S. (2003). Measurement of IgG antibodies to Chlamydia trachomatis by commercial enzyme immunoassays and immunofluorescence in sera from pregnant women and patients with infertility, pelvic inflammatory disease, ectopic pregnancy, and laboratory diagnosed Chlamydia psittaci/Chlamydia pneumoniae infection. Journal of Clinical Pathology, 56(3), 225-229.

19. Moss, T. R. \& Darougar, S. (2001). Human genital infections with Chlamydia trachomatis - is there a role for serology? In: International handbook of Chlamydia [ed. Moss, T. R.] pp 33 - 47. Euromed Publications Ltd., Haslemere UK, ISBN 1899015434

20. OSTERGAARD, L. (1999). Diagnosis of urogenital Chlamydia trachomatis infection by use of DNA amplification. APMIS, 107(S89), 5-36.

21. Hadgu, A. (1996). The discrepancy in discrepant analysis. The Lancet, 348(9027), 592-593.

Tanaka, M., Nakayama, H., Yoshida, H., Takahashi, K., Nagafuji, T., Hagiwara, T., \&Kumazawa, J. (1998). Detection of Chlamydia trachomatis in vaginal specimens from female commercial sex workers using a new improved enzyme immunoassay. Sexually Transmitted Infections, 74(6), 435-438.

22. Meyer, T. (2016). Diagnostic Procedures to Detect Chlamydia trachomatis Infections. Microorganisms, 4(3), 25.

23. Ivo, D. (2006). Introduction to statistical methods for the life and health sciences.Uinversity of Califorina Los Angels.Http://www.stat.ucla.edu/-dinov/courses-students.

24. Verkooyen, R. P., Peeters, M. F., Van Rijsoort-Vos, J. H., Van Der Meijden, W. I., \& Mouton, J. W. (2002). Sensitivity and specificity of three new commercially available Chlamydia trachomatis tests. International Journal of STD \& AIDS, 13(1_suppl), 23-25.

25. Chernesky, M. A., Mahony, J. B., Castriciano, S., Mores, M., Stewart, I. O., Landis, S. J., and Leman, C. (1986). Detection of Chlamydia trachomatis Antigens by Enzyme Immunoassay and Immunofluorescence in Genital Specimens from Symptomatic and Asymptomatic Men and Women. Journal of Infectious Diseases, 154(1), 141-148.

26. Rapoza, P. A. (1986). Assessment of neonatal conjunctivitis with a direct immunofluorescent monoclonal antibody stain for Chlamydia. JAMA: The Journal of the American Medical Association, 255(24), 3369-3373.

27. Smith, J. W., R. E. Rogers, B. P. Katz, J. F. Brickler, P. L. Lineback, B. VanderPol, and R. B. Jones. (1987). Diagnosis of chlamydial infection in women attending antenatal and gynecologic clinics. Journal of Clinical Microbiology, 25(5), 868-872.

28. Carolyn, M. B. (1997) Current Methods of Laboratory Diagnosis of C.trachomatisInfections.Clinical Microbiology reviews, 10(1):160-184.

29. Thejls, H., Gnarpe, J., Gnarpe, H., Larsson, P. G., Platz-Christensen, J. J., Ostergaard, L., \& Victor, A. (1994). Expanded gold standard in the diagnosis of Chlamydia trachomatis in a low prevalence population: diagnostic efficacy of tissue culture, direct immunofluorescence, enzyme immunoassay, PCR and serology. Sexually Transmitted Infections, 70(5), 300-303. 
30. Mohammed, H. Iqbal, Al-Awadei, J. Salwa, Saadedin, M.K. Shurook. (2017). Molecular diagnosis ofChlamydia trachomatis in infertile women using Real time PCR and comprise with other methods.Iraqi Journal of science,58(3B), 1437-1446.

31. Nuñez-Forero, L., Moyano-Ariza, L., Gaitán-Duarte, H., Ángel-Müller, E., Ruiz-Parra, A., González, P.,Tolosa, J. E. (2015). Diagnostic accuracy of rapid tests for sexually transmitted infections in symptomatic women. Sexually Transmitted Infections, 92(1), 24-28.

32. Centers for Disease Control and Prevention. Screening Tests to Detect Chlamydia trachomatis and Neisseria gonorrhoeae Infections - 2002. MMWR 2002;51(No. RR-15): [page 8]. 